\title{
Research
}

Dionne Kringos, Wienke Boerma, Yann Bourgueil, Thomas Cartier, Toni Dedeu, Toralf Hasvold, Allen Hutchinson, Margus Lember, Marek Oleszczyk, Danica Rotar Pavlic, Igor Svab, Paolo Tedeschi, Stefan Wilm, Andrew Wilson, Adam Windak, Jouke Van der Zee and Peter Groenewegen

\section{The strength of primary care in Europe:}

\author{
an international comparative study
}

\begin{abstract}
Background

A suitable definition of primary care to capture

the variety of prevailing international organisation and service-delivery models is lacking.

\section{Aim}

Evaluation of strength of primary care in Europe.

Design and setting

International comparative cross-sectional study performed in 2009-2010, involving 27 EU member states, plus Iceland, Norway, Switzerland, and Turkey.
\end{abstract}

\section{Method}

Outcome measures covered three dimensions of primary care structure: primary care governance, economic conditions of primary care, and primary care workforce development; and four dimensions of primary care service-delivery process: accessibility, comprehensiveness, continuity, and coordination of primary care. The primary care dimensions were operationalised by a total of 77 indicators for which data were collected in 31 countries. Data sources included national and international literature, governmental publications, statistical databases, and experts' consultations.

\section{Results}

Countries with relatively strong primary care are Belgium, Denmark, Estonia, Finland, Lithuania, the Netherlands, Portugal, Slovenia, Spain, and the UK. Countries either have many primary care policies and regulations in place, combined with good financial coverage and resources, and adequate primary care workforce conditions, or have consistently only few of these primary care structures in place. There is no correlation between the access, continuity, coordination, and comprehensiveness of primary care of countries.

\section{Conclusion}

Variation is shown in the strength of primary care across Europe, indicating a discrepancy in the responsibility given to primary care in national and international policy initiatives and the needed investments in primary care to solve, for example, future shortages of workforce. Countries are consistent in their primary care focus on all important structure dimensions. Countries need to improve their primary care information infrastructure to facilitate primary care performance management.

\section{Keywords}

benchmarking, Europe; delivery of health care; general practice; primary health care.

\section{INTRODUCTION}

Important drivers for health systems development are the need for greater responsiveness to the population's health needs and greater cost effectiveness. ${ }^{1-4}$ Healthcare systems should produce better health as set forth, for example, in the United Nation's Millennium Development Goals, 4,5 the World Health Assembly 2009, ${ }^{2}$ and the World Health Report 2008. ${ }^{6}$ Strong primary care contributes to a better functioning of healthcare systems overall. This was, for example, acknowledged by the recent Affordable Care Act and the introduction of medical care homes in the US. ${ }^{7}$ Primary care is the first level of professional care service, where people present their health problems, and where the majority of the population's curative and preventive health needs can be satisfied. ${ }^{1}$ Current challenges of healthcare systems include new risk factors, ageing populations, health inequities, increasingly complex needs, rising healthcare expenditures, technological change, and a lack of human

D Kringos, postdoctoral health systems researcher, Academic Medical Centre of the University of Amsterdam, Department of Social Medicine, the Netherlands. W Boerma, senior researcher; P Groenewegen, director of NIVEL, Netherlands Institute for Health Services Research, The Netherlands. Y Bourgueil, director; T Cartier, MD, researcher, Institute for Research and Information in Health Economics (IRDES), France. T Dedeu, MD, policy advisor, IDIAP, Jordi Gol Foundation, Spain. T Hasvold, professor, Department of Community Medicine ISM, Faculty of Health Sciences, University of Troms $\varnothing$, Norway. A Hutchinson, MD, professor, School of Health and Related Research ScHARR, University of Sheffield, Sheffield, UK. M Lember, MD, professor, Department of Internal Medicine Tartu University Hospital, Estonia. M Oleszczyk MD, researcher, Department of Family Medicine, Jagiellonian University Medical College, Poland. D Rotar Pavlic, MD, assistant professor; I Svab, MD, professor, Department of Family Medicine, University of Ljubljana, Slovenia. P Tedeschi, policy advisor, Regione Toscana, Florence, Italy. S Wilm, head, Institute of General Practice. resources. ${ }^{8-11}$ Supported by a growing body of evidence since Starfield's study in 1994, ${ }^{12}$ decision makers increasingly use the strengthening of primary care in their strategy to cope with these challenges. ${ }^{13,14}$

This study has built on previous studies that have evaluated primary care in individual countries, ${ }^{15,16}$ or made international comparisons of a limited set of functions. ${ }^{17,18}$ A major challenge in international comparative studies in primary care is to develop a suitable definition of primary care that can capture the variety in prevailing organisation and service-delivery models.

This study seeks to overcome prevalent limitations in primary care research, by comparing the strength of primary care in 31 European countries, using a standardised measurement instrument.

The study is based on the results of the EU-funded PHAMEU (Primary Health Care Activity Monitor for Europel project, to evaluate the strength of primary care structures and the service-delivery

University Hospital, Düsseldorf, Germany. A Wilson, professor, Department of Health Sciences, University of Leicester, Leicester, UK A Windak, MD, professor, Department of Family Medicine, Jagiellonian University Medical College, Poland. J van der Zee, professor, Faculty of Health Sciences, Department of International Public Health, University of Maastricht, The Netherlands.

\section{Address for correspondence}

Dionne Kringos, Academic Medical Centre, University of Amsterdam, Social Medicine, Meibergdreef 9, Amsterdam, 1105 AZ,

Netherlands.

E-mail: d.s.kringosdamc.uva.nl

Submitted: 23 April 2013; Editor's response: 24 May 2013; final acceptance: 9 August 2013 CBritish Journal of General Practice

This is the full-length article (published online 28 Oct 2013) of an abridged version published in print. Cite this article as: Br J Gen Pract 2013; DOI: 10.3399/bjgp13X674422 


\section{How this fits in}

Strong primary care is supposed to improve the capacity of a country to achieve a responsive, high-quality and cost-effective healthcare system. Policymakers are concerned about the development of primary care, as shown by the wealth of charters, resolutions, and statements that continue to originate from governments and non-governmental organisations worldwide. So far, little attention has been paid to systematically measuring the strength of primary care in Europe, hampering primary care performance benchmarking, management, and improvement. The European primary care monitoring instrument applied in this study facilitates comparison and analysis of the key functions of primary care in a standardised way.

process. The instrument, developed in 2008-2009, and the subsequent data collection in 31 European countries, has resulted in a standardised comparison and analysis of key dimensions (or functions) of primary care. 119 The instrument has been developed on the basis of scientific evidence and consensus among an international panel of experts. The starting point was a systematic literature review to identify the core dimensions of primary care. ${ }^{1}$ Based on the results of the literature review, it was identified that strong primary care consists of seven core dimensions at the structure and process (service-delivery) level of primary care (Figure 1). ${ }^{19}$

The structure of primary care consists of three dimensions:

1. primary care governance;

2. economic conditions of primary care; and

3. primary care workforce development.

The primary care process is determined by four dimensions:

4. accessibility of primary care;

5. comprehensiveness of primary care;

6. continuity of primary care; and

7. coordination of primary care.

In terms of the dimensions identified strong primary care provides accessible, comprehensive care, in an ambulatory setting, to patients in their own context on a continuous basis, and coordinates the care processes of patients across the healthcare system, supported by an appropriate structure of primary care governance, economic conditions, and a sufficiently developed primary care workforce. Variation between countries in the strength of their primary care refers to different degrees in which the above-mentioned dimensions have been developed.

For each of these dimensions, the available literature provided evidence showing that primary care contributes through these dimensions to overall health system performance and population health. Based on the systematic literature review and subsequent expert consultations, 77 indicators were developed to measure the primary care dimensions as described by Kringos et al, 2010 (Figure 1). ${ }^{19}$

This current paper aims to answer the following questions:

1. To what extent do the structure and process measures of primary care vary at the national level?

2. Do positions on a structural primary care dimension predict performance on process dimensions?

3. Can countries be ranked on the basis of their position on both structural and process dimensions; and what is distinctive about countries on both extremes?

\section{METHOD}

\section{Data collection}

On the basis of the primary care indicator set, ${ }^{19}$ data were collected by the PHAMEU project partners between January 2009 to December 2010 in 31 countries lincluding 27 EU member states, Iceland, Norway, Switzerland, and Turkey), using a uniform data-collection strategy. For some indicators, data were available in international databases or scientific publications. These sources were complemented by national sources Ifor example, literature databases or websites of national statistical offices and important healthcare stakeholders), as far as accessible in languages known to the project team. Furthermore, national experts were consulted to get access to grey literature or articles in a language unknown to the project team, to help find missing information or to deliver consensus-based information, and to validate the country results.

On average, countries had any data available on $94 \%$ of the primary care structure indicators; and $93 \%$ of the primary care service-delivery process indicators. 


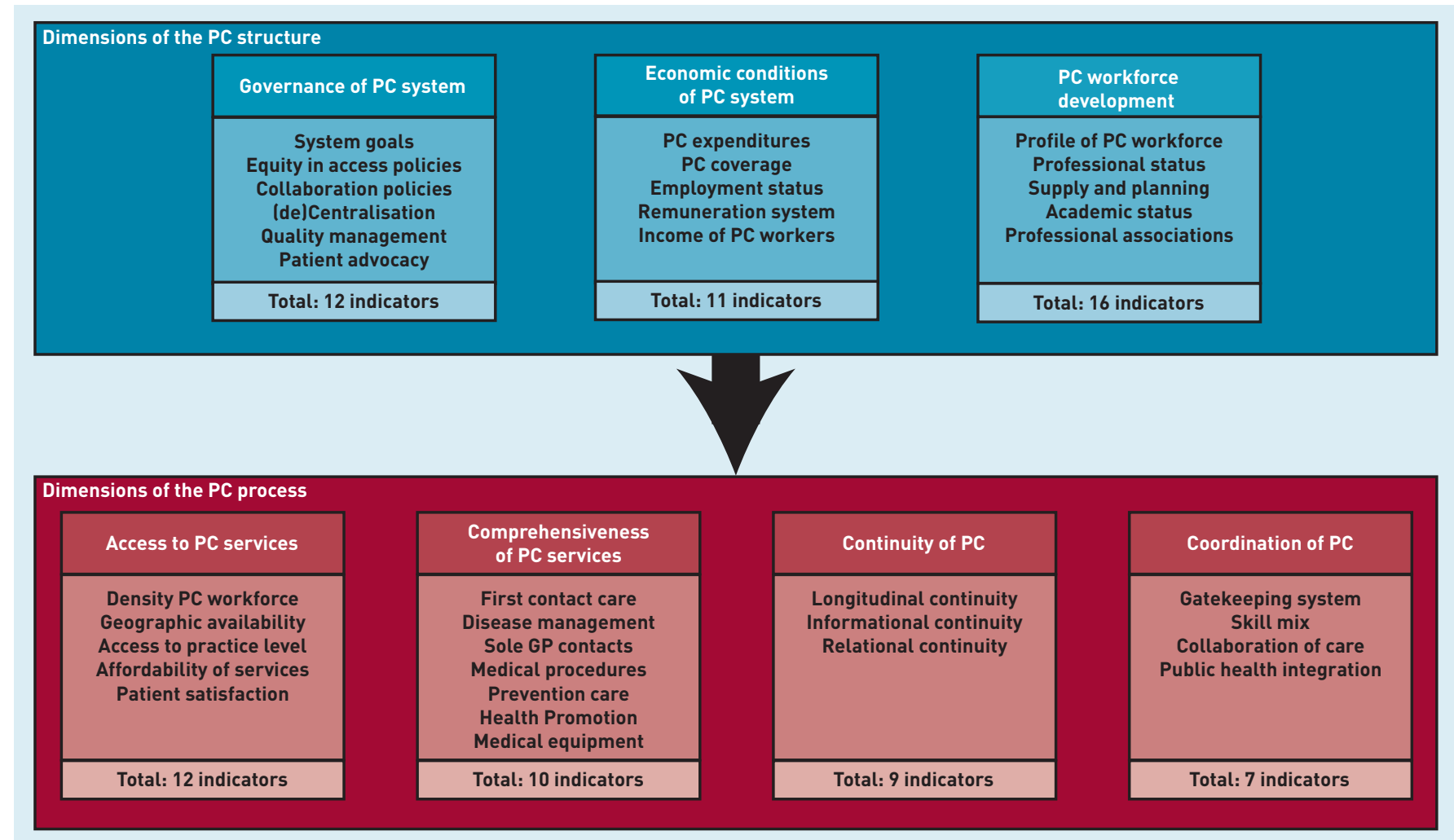

Figure 1. Primary care structure and process dimensions. $P C=$ primary care.
At the level of primary care structure, there were fewest data $(91 \%)$ on economic conditions; and at the level of primary care service-delivery process fewest data were available on continuity of care (87\%). Countries vary more on the availability of data on primary care service-delivery process indicators, than primary care

\section{Box 1. Dimension scoring.}

\section{Scoring qualitative and quantitative indicators}

The European Primary Care Monitor consisted of a mix of quantitative and qualitative indicators. The scoring of qualitative indicators was based on the findings of the systematic literature review on primary care.

For example, if a country indicated having a pro-primary care policy in place, or reimbursing primary care providers by a mixture of fee for service, capitation, and performance indicators, the country scored a ' 3 ' on the respective indicators, meaning a feature of strong primary care. The scoring of quantitative indicators was based on the literature review, to determine the direction of scoring (strong, medium, or weak primary care), and the distribution of data on the respective indicator among all 31 countries. The limits of strong (3), medium (2), and weak (1) scores were determined by the $33 \%$ and $67 \%$ percentiles of valid country results. In this way, the data show the relative levels of primary care strength across Europe. For example, primary care expenditure (as a percentage of total health expenditure) ranged from 25.6\% (Switzerland) to 4.7\% (Czech Republic). One-third of the countries had a primary care expenditure ranging from $4.7 \%$ to $9.8 \%$, and therefore scored ' 1 '; one-third of the countries had a primary care expenditure ranging from $9.8 \%$ to $14.0 \%$, scoring ' 2 '; and the remaining one-third of the countries with expenditures of $14.0 \%$ or higher scored ' 3 '. The only indicator of the European Primary Care Monitor that was excluded from scoring was the employment status of GPs, owing to lack of evidence of its effect on healthcare system outcomes.

\section{Calculating dimension scores}

A two-level hierarchical latent regression model was used to calculate separate dimension scores based on the indicators by country. The dependent variable was the scores for every country on the indicators belonging to that dimension. In the fixed part of the model, the dimension average was estimated together with the indicator effects (using deviation indicator coding), to control for differences in the indicator averages. In the random part, at level one, the indicator measurement errors were modelled as separate variance terms for every indicator; this controls for differences in the indicators' standard deviations. At level two, the effect for every country on the dimension was modelled; this was used to calculate country dimension scores. The reliability coefficients (ranging from 0.53 to 0.57 ) were well within the acceptable range for the scales to be considered reliable. Only two scales (economic conditions and continuity of care) had a low reliability coefficient $(0.26$ and 0.35 respectively), which indicated a relatively large amount of missing data. 
Table 1. Availability of data on primary care indicators, by dimension and country

\begin{tabular}{|c|c|c|c|c|c|c|c|c|c|}
\hline \multirow[b]{2}{*}{ Country } & \multicolumn{8}{|c|}{ Percentage of indicators (including subquestions with available data, by dimension and country) } & \multirow[b]{2}{*}{ Mean \% } \\
\hline & $\begin{array}{c}\text { Primary } \\
\text { care } \\
\text { governance } \\
(n=16)\end{array}$ & $\begin{array}{l}\text { Economic } \\
\text { conditions of } \\
\text { primary care } \\
(n=10)\end{array}$ & $\begin{array}{l}\text { Primary care } \\
\text { workforce } \\
\text { development } \\
{[n=17)}\end{array}$ & Mean \% & $\begin{array}{c}\text { Access } \\
\text { to } \\
\text { primary care } \\
(n=19)\end{array}$ & $\begin{array}{c}\text { Continuity } \\
\text { of } \\
\text { primary care } \\
\text { (n=12) }\end{array}$ & $\begin{array}{c}\text { Coordination of } \\
\text { primary care } \\
{[n=9]}\end{array}$ & $\begin{array}{l}\text { mprehensiveness } \\
\text { of } \\
\text { primary care } \\
(n=10)\end{array}$ & \\
\hline Austria & 100 & 90 & 100 & 97 & 100 & 75 & 100 & 100 & 94 \\
\hline Belgium & 100 & 100 & 100 & 100 & 100 & 100 & 100 & 90 & 98 \\
\hline Bulgaria & 100 & 100 & 100 & 100 & 100 & 100 & 100 & 100 & 100 \\
\hline Cyprus & 94 & 80 & 71 & 81 & 95 & 50 & 100 & 70 & 79 \\
\hline Czech Republic & 100 & 100 & 100 & 100 & 95 & 75 & 100 & 100 & 92 \\
\hline Denmark & 100 & 89 & 100 & 96 & 100 & 92 & 100 & 100 & 98 \\
\hline Estonia & 100 & 100 & 100 & 100 & 100 & 92 & 100 & 100 & 98 \\
\hline Finland & 100 & 89 & 94 & 94 & 95 & 92 & 100 & 100 & 97 \\
\hline France & 100 & 100 & 100 & 100 & 100 & 92 & 100 & 100 & 98 \\
\hline Germany & 100 & 90 & 100 & 97 & 100 & 100 & 100 & 100 & 100 \\
\hline Greece & 50 & 70 & 94 & 71 & 89 & 67 & 56 & 70 & 70 \\
\hline Hungary & 100 & 100 & 100 & 100 & 100 & 100 & 100 & 100 & 100 \\
\hline Iceland & 75 & 80 & 100 & 85 & 84 & 75 & 78 & 100 & 84 \\
\hline Ireland & 100 & 89 & 100 & 96 & 84 & 75 & 100 & 90 & 87 \\
\hline Italy & 100 & 100 & 94 & 98 & 95 & 58 & 100 & 90 & 86 \\
\hline Latvia & 100 & 100 & 100 & 100 & 95 & 100 & 100 & 100 & 99 \\
\hline Lithuania & 100 & 100 & 100 & 100 & 100 & 100 & 100 & 100 & 100 \\
\hline Luxembourg & 100 & 90 & 94 & 95 & 89 & 67 & 89 & 90 & 84 \\
\hline Malta & 94 & 60 & 59 & 71 & 68 & 67 & 100 & 60 & 74 \\
\hline Netherlands & 100 & 100 & 100 & 100 & 100 & 100 & 100 & 100 & 100 \\
\hline Norway & 100 & 100 & 88 & 96 & 84 & 100 & 89 & 100 & 93 \\
\hline Poland & 100 & 100 & 88 & 96 & 95 & 92 & 100 & 90 & 94 \\
\hline Portugal & 100 & 89 & 100 & 96 & 100 & 100 & 100 & 100 & 100 \\
\hline Romania & 100 & 80 & 100 & 93 & 95 & 100 & 89 & 80 & 91 \\
\hline Slovak Republic & 100 & 100 & 100 & 100 & 100 & 100 & 100 & 100 & 100 \\
\hline Slovenia & 100 & 100 & 76 & 92 & 89 & 100 & 89 & 100 & 95 \\
\hline Spain & 100 & 100 & 94 & 98 & 89 & 100 & 100 & 100 & 97 \\
\hline Sweden & 100 & 80 & 82 & 87 & 95 & 67 & 100 & 90 & 88 \\
\hline Switzerland & 100 & 100 & 100 & 100 & 63 & 67 & 100 & 100 & 82 \\
\hline Turkey & 100 & 60 & 100 & 87 & 100 & 100 & 100 & 90 & 98 \\
\hline UK & 100 & 100 & 100 & 100 & 100 & 100 & 100 & 90 & 98 \\
\hline Mean \% & 97 & 91 & 95 & - & 94 & 87 & 96 & 94 & - \\
\hline
\end{tabular}

structure indicators (Table 1). On average, $12 \%$ of all data were based on official national and/or international statistics, $17 \%$ on governmental publications, $15 \%$ on scientific reports or articles, $11 \%$ on internet documents or websites, $4 \%$ on published books, and $41 \%$ on experts estimations, opinions, or experiences.

\section{Measuring primary care strength}

Country data on the indicators were obtained and transformed into scores indicating the strength of each indicator in each country, ranging from 1 (weak) to 3 (strong) (see Kringos, 2013, ${ }^{20}$ for an overview of the scoring system by indicator). A similar approach was used in earlier work by Macinko et al. ${ }^{18}$ Based on these indicators, seven separate dimension scores were calculated for each country, by means of a two-level hierarchical latent regression model (Box 1). Such models result in valid dimension scores even if countries have missing indicators. MLWiN 2.02 and SPSS/PASW 18.0 software were used 


\section{RESULTS}

\section{Primary care governance}

Not all countries have a clear governmental vision on the future of primary care. In a majority of countries, important governance functions (for example, priority setting and supply planningl have been decentralised to regional and/or local authorities. Quality of care is safeguarded by minimum standards in most countries, including professional education, clinical guidelines, and patient rights. Rules for continuing medical education are often absent, and clinical guidelines for use in primary care are often made by medical specialists or ministries of health.

\section{Economic conditions of primary care}

There is a clear East-West divide in Europe in the relative level of healthcare expenditures and providers' income. The income of primary care providers in Eastern Europe is often much lower than the income of medical specialists. In most European countries, GPs are independent entrepreneurs contracted to the healthcare system. Remuneration for GPs is often topped up by various performance-related financial incentives.

\section{Primary care workforce development}

In most countries, GPs are the most common providers of primary care. In some countries, some medical specialties are directly accessible functions in primary care. Workforce challenges are the ageing of workers and insufficient replacement, resulting in possible shortages in the next decade. On average, one-fifth of all medical graduates choose to enrol in postgraduate training in family medicine/general practice. Only half of the countries have data available from workforce-capacity and forecasting studies of primary care. In Europe it is more common for GPs to be organised in national associations or colleges than it is for primary care nurses.

\section{Accessibility of primary care}

Geographically, GPs are unevenly distributed within the countries. In almost half of the countries, there are financial obstacles to seeing a GP, as patients often need to pay part of the costs of a visit. Organisational arrangements to facilitate access leave ample room for improvement, particularly considering telephone and email consultations, appointment systems, and offering consultations for special patient groups. Also, the chance of receiving a home visit by a GP differs strongly across Europe. After-hours primary care is organised in different ways. Such services can be provided by GPs leither on a rota basis or in larger structures like GP cooperatives), or by special services in which GPs are not involved. In a few countries (Cyprus, Estonia, Latvia, and Lithuania), hospital emergency departments still have the sole responsibility for after-hours care.

\section{Comprehensiveness of primary care}

Overall, the most comprehensive set of primary care services, both curative and preventive, is offered in Belgium, Bulgaria, Finland, France, Lithuania, Norway, Portugal, Spain, Sweden, and the UK. Primary care facilities are generally well equipped across Europe. The role of GPs as first-contact care providers is better developed in countries with a referral system.

GPs provide follow-up care for a broader scope of conditions in countries where solo practice is more dominant. The involvement of primary care practice nurses in the provision of medical technical procedures is marginal. Preventive care activities are provided in most countries, by a large variety of providers, including GPs.

\section{Continuity of primary care}

Registration of patients with a GP office is beneficial for the continuity of primary care. Such a 'list system' is not used in Austria, Belgium, Cyprus, France, Germany, Ireland, Luxembourg, Malta, Sweden, or Switzerland, as patients in these countries have free choice to visit any GP. However, even in these countries, many people usually visit the same GP. Relatively large patient lists are found in Austria, Finland, Germany, and the Netherlands. Considering informational and interpersonal continuity of care, improvements are possible; for example, by offering primary care providers more adequate software and training to use it. Computers in primary care practices are not frequently used for advanced purposes, such as prevention and public health activities, information exchange with peers, and medical record keeping. Patients are relatively dissatisfied with primary care providers' communication skills and the duration of the consultation (for example in Germany, Lithuania, and the UK). Satisfaction is higher with the relationship they have with their primary care provider and explanation provided by this provider on options for treatment.

\section{Coordination of primary care}

Referral systems are major conditions for coordination, and are in place in some 
form in most European countries. In about half of the countries (14), such a system is obligatory for visiting all, or most, medical specialists. These are Bulgaria, Estonia, Hungary, Italy, Latvia, Lithuania, the Netherlands, Norway, Portugal, Romania, Slovenia, Spain, Sweden, and the UK. In 10 countries (Czech Republic, Denmark, Finland, France, Greece, Iceland, Ireland, Malta, Poland, Slovak Republic), a visit to a medical specialist without a referral has financial implications in terms of out-ofpocket payments. Obstacles to directly visiting medical specialists are absent or low in Austria, Belgium, Cyprus, Germany, Luxembourg, Switzerland, and Turkey.
In almost half of the countries in Europe, solo general practice is the dominant form. GPs working in shared practices have more face-to-face meetings with colleagues and more often offer special clinical sessions than do those in single-handed practices. Cooperation and coordination between GPs and medical specialists is problematic in many countries. In general, nurses have limited tasks in primary care, although there are some notable exceptions, for example in the UK and Spain.

\section{The strength of primary care by} dimension

Table 2 provides an overview of the strength

Table 2. The strengths of countries' primary care dimensions based on scoring system (see Box 2)

\begin{tabular}{|c|c|c|c|c|c|c|c|c|}
\hline \multirow[b]{2}{*}{ Country } & \multicolumn{3}{|c|}{ The structure of primary care } & \multicolumn{4}{|c|}{ The service-delivery process of primary care } & \multirow{2}{*}{$\begin{array}{c}\text { Overall } \\
\text { primary } \\
\text { care system } \\
\text { strength }\end{array}$} \\
\hline & $\begin{array}{c}\text { Primary } \\
\text { care } \\
\text { governance }\end{array}$ & $\begin{array}{l}\text { Economic } \\
\text { conditions of } \\
\text { primary care }\end{array}$ & $\begin{array}{c}\text { Primary care } \\
\text { workforce } \\
\text { development }\end{array}$ & $\begin{array}{c}\text { Access to } \\
\text { primary care }\end{array}$ & $\begin{array}{l}\text { Continuity of } \\
\text { primary care }\end{array}$ & $\begin{array}{l}\text { Coordination } \\
\text { of primary care }\end{array}$ & $\begin{array}{l}\text { Comprehensiveness } \\
\text { of primary care }\end{array}$ & \\
\hline Austria & Medium & Medium & Weak & Medium & Weak & Weak & Weak & Weak \\
\hline Belgium & Medium & Strong & Medium & Weak & Strong & Medium & Strong & Strong \\
\hline Bulgaria & Medium & Weak & Weak & Weak & Medium & Weak & Strong & Weak \\
\hline Czech Republic & Medium & Weak & Weak & Strong & Strong & Medium & Weak & Medium \\
\hline Denmark & Strong & Medium & Strong & Strong & Strong & Strong & Medium & Strong \\
\hline Estonia & Strong & Weak & Medium & Medium & Strong & Medium & Medium & Strong \\
\hline Finland & Medium & Strong & Strong & Medium & Medium & Medium & Strong & Strong \\
\hline France & Medium & Medium & Medium & Weak & Medium & Medium & Strong & Medium \\
\hline Germany & Medium & Strong & Medium & Medium & Strong & Weak & Medium & Medium \\
\hline Hungary & Weak & Medium & Medium & Strong & Medium & Weak & Weak & Weak \\
\hline Iceland & Weak & Weak & Weak & Medium & Strong & Weak & Medium & Weak \\
\hline Ireland & Weak & Weak & Strong & Weak & Strong & Weak & Medium & Weak \\
\hline Italy & Strong & Strong & Medium & Medium & Weak & Medium & Weak & Medium \\
\hline Latvia & Medium & Medium & Weak & Weak & Strong & Medium & Medium & Medium \\
\hline Lithuania & Strong & Medium & Medium & Strong & Weak & Strong & Strong & Strong \\
\hline Luxembourg & Weak & Weak & Weak & Weak & Weak & Medium & Medium & Weak \\
\hline Malta & Weak & Weak & Strong & Weak & Weak & Strong & Medium & Weak \\
\hline Netherlands & Strong & Strong & Strong & Strong & Weak & Strong & Medium & Strong \\
\hline Norway & Strong & Weak & Medium & Medium & Medium & Weak & Strong & Medium \\
\hline Poland & Weak & Weak & Weak & Strong & Medium & Strong & Weak & Medium \\
\hline Portugal & Strong & Medium & Strong & Strong & Medium & Medium & Strong & Strong \\
\hline Slovak Rep. & Weak & Medium & Weak & Medium & Strong & Weak & Weak & Weak \\
\hline Slovenia & Strong & Strong & Strong & Strong & Weak & Strong & Weak & Strong \\
\hline Spain & Strong & Strong & Strong & Strong & Strong & Strong & Strong & Strong \\
\hline Sweden & Medium & Medium & Medium & Medium & Weak & Strong & Strong & Medium \\
\hline Switzerland & Weak & Medium & Strong & Weak & Medium & Medium & Medium & Medium \\
\hline Turkey & Medium & Medium & Medium & Weak & Weak & Weak & Medium & Weak \\
\hline UK & Strong & Strong & Strong & Strong & Medium & Strong & Strong & Strong \\
\hline
\end{tabular}




\section{Box 2. Similarities between countries with strong primary care}

Countries with strong overall primary care share certain features, such as the pre-eminence of GPs as the key focal point of primary care provision, including the following duties:

- to be the main point of entry to the rest of the healthcare system, whether it is inscribed in a national policy (gatekeeping) or not. For this reason, the majority of countries have developed national policies of various types to ensure both geographical and financial access to GPs. This role of first-contact care can sometimes be shared with nurses (for example in Finland and the UK) as a supplementation policy to enhance primary care accessibility;

- to take a medical advocacy role for individual patients: in all countries, they monitor diagnosis, therapy, prevention, and follow-up activities, although some fine differences still exist;

- to coordinate patient care, both within and outside primary care. The modalities of this cooperation can be very diverse throughout Europe, but they play the same essential role.

The second major element of similarity between countries with strong primary care is the formal commitment to universal access to primary care. With the exceptions of Cyprus, Ireland, and Latvia, all countries tend to lower the primary care co-payments as much as possible, particularly for general practice visits. For medicines in primary care, things are a little less idyllic, with only four countries having no charge. A common tool for co-payment regulation in insurance-based systems is the existence of deductibles, such as in Germany, the Netherlands, or Switzerland. Nevertheless, in all countries, specific policies have been designed to ensure accessibility for the lowest incomes, the elderly, patients with chronic conditions or disabilities, or children and pregnant women. The current state of financial access to primary care is mainly based on the population dimension of universal coverage, less on direct costs, and even less on comprehensiveness of services: there is still room for improvement regarding universal coverage in Europe.

Also, non-EU countries (Norway, Switzerland, and Turkey) pursue equivalent goals and features regarding the general practice position, universal coverage, and other components of primary care.

Other aspects of primary care systems could be found as common features of countries lfor example, policies in favour of patient's rights, of geographical equity in distribution of primary care human resources, or of academic development of general practice) but none of them offer the same level of similarity compared to the earlier described features in this box. of coordination of primary care.

Taking the performance on all dimensions into consideration, the last column of Table 2 shows the overall strength of primary care in each country. Box 2 highlights the commonalities between countries with strong overall primary care.

\section{DISCUSSION}

\section{Summary}

This study has shown that countries tend to have a consistent primary care orientation on all three structure dimensions. It makes sensethat countriesthat prioritisesupportive policies for primary care also invest more in primary care and the development of its workforce, and vice versa. Surprisingly, there is no strong correlation between the accessibility, comprehensiveness, continuity, and coordination of primary care of countries. This study also shows that in almost all countries, high-quality primary care information on aspects of comprehensiveness was lacking.

\section{Strengths and limitations}

This study is based on a unique, rich, comparable, up-to-date dataset on primary care in 31 European countries. However, by depending on the availability of data, the quality of data in terms of completeness and timeliness differs across Europe. In particular, the reliance on expert opinion may have affected some of the results, as experts may base their judgements not only on the objective current status or shortcomings of their country's primary care, but also on the prospects of innovation or concerns of decline in the near future. Although this may have influenced the results, it also raises awareness of primary care information infrastructures in Europe. In addition, countries may have strong primary care on paper, but practice may need time to implement this or catch up, and vice versa. These are complications and dynamics within a system that are difficult to measure.

It is possible there is more variation in the structure and service-delivery process of primary care than this study was able to capture, by using the country level as a unit of analysis instead of, for example, regions.

\section{Comparison with existing literature}

Macinko and colleagues measured the primary care strength of 14 European Organisation for Economic Co-operation and Development (OECD) countries in 1995..$^{18}$ Although the results of the present study are not fully comparable, owing to differences in methodology, it has shown 
that in 2009-2010, the primary care strength of Denmark, Greece, Italy, the Netherlands, Norway, Spain, Sweden, and the UK has remained constant, whereas it has improved in Belgium, Finland, France, Germany, Portugal, and Switzerland. Moreover, it is safe to assume that the Central and Eastern European countries have improved their primary care strength since the early 1990s, when they started to transform their healthcare systems. Many of these countries have retrained district doctors and primary care-led clinic specialists into GPs and introduced gatekeeping. ${ }^{21}$

\section{Implications for research and practice}

The implications of these findings suggest the strength of primary care should be approached as a multidisciplinary phenomenon, consisting ofthreedimensions at structure level that can be summarised by one score lalthough separate scores will probably be more informative to identify areas for improvement); and four separate dimensions at primary care service-delivery level. However, awareness should be raised about the changes that each of the primary care dimensions may undergo through time. For example, with the increasing prevalence and comorbidity of chronic diseases, the dimension of coordination of care is gaining importance. This makes it important to consider the context of primary care when trying to understand the state of primary care in countries at a certain point in time.

The lack of correlation among process dimensions suggests that each of the primary care service-delivery process dimensions can independently be targeted for policy-improvement actions. It is questionable, however, whether the various primary care service-delivery process dimensions are equally important in contributing to the outcomes of a healthcare system. Future research could address the appropriateness of using a weighting system for primary care dimensions to answer this question.

If countries aim to improve their primary care strength, there are a number of common issues that would need to be addressed across Europe. For example, it is worrying that there is not always a clear governmental vision on the future direction of primary care, particularly because most countries have decentralised important primary care functions. Although decentralisation can increase the responsiveness of primary care at regional or local level, there is a risk of interregional inequities in access, financing, quality of care, and, ultimately health.

There is an urgent need for countries to take appropriate measures to tackle the threatened workforce shortages. These could include a regular system of workforce-capacity planning, raising the (financial) attractiveness of the profession, and increasing possibilities for task substitution. Perhaps the highest gains in access can be made by reducing the level of primary care copayments, to increase affordability for patients. The highest (formal) payments in the public system exist in Ireland, where patients without a medical card (about $70 \%$ of the population) pay $€ 60$ to $€ 80$ for each general practice visit, with no reimbursement. Countries should make a clear choice between demand regulation via easily accessible (gatekeeping) GPs or via copayments. Cooperation and coordination between primary and secondary care might benefit from the creation of multidisciplinary professional education, teamwork, and multidisciplinary practices.

The degree and quality of data about primary care available shows the potential capacity of countries to evaluate and monitor the state of their primary care, identify areas needing improvement, and be accountable and transparent on system performance. If primary care continues to be given a vital role in achieving healthcare system outcomes, there is an urgent need to invest more in improving the primary care information infrastructures, at both national and international level.

To conclude, this study offers a valuable baseline measurement of (the multidimensionality of) primary care, but it will lose its value if this is not used as a basis for primary care management and routine data collection.
General Practice Research Network, the World Health Organization Regional Office for Europe, and the European Public Health Association. Special thanks are extended to the other experts who contributed to the data collection in their country.

\section{Discuss this article}

Contribute and read comments about this article on the Discussion Forum: http://www.rcgp.org.uk/bjgp-discuss 


\section{REFERENCES}

1. Kringos DS, Boerma WGW, Hutchinson A, et al. The breadth of primary care: a systematic literature review of its core dimensions. BMC Health Serv Res 2010; 10(1): 65 .

2. Sixty-Second World Health Assembly. Primary health care, including health system strengthening. Resolution WHA62.12, 22 May 2009. http://uww.who.int/ hrh/resources/A62_12_EN.pdf (accessed 9 Sep 2013).

3. Travis P, Bennett S, Haines A, et al. Overcoming health-systems constraints to achieve the Millennium Development Goals. Lancet 2004; 364(9437): 900-906.

4. United Nations. A/RES/55/2: United Nations Millennium Declaration: resolution adopted by the General Assembly. New York, NY: United Nations, 2000.

5. De Maeseneer J, van Weel C, Roberts R. Family medicine's commitment to the MDGs. Lancet 2010; 375(9726):1588-1589.

6. World Health Organization. The World Health Report 2008: primary health care now more than ever. Geneva: World Health Organization, 2008.

7. Rohde J, Cousens S, Chopra M, et al. 30 years after Alma-Ata: has primary health care worked in countries? Lancet 2008; 372(9642): 950-961.

8. Hongoro C, McPake B. How to bridge the gap in human resources for health Lancet 2004; 364(9443): 1451-1456.

9. Mackenbach JP, Meerding WJ, Kunst AE. Economic costs of health inequalities in the European Union. J Epidemiol Community Health 2010; 65(5): 412-419.

10. Mills M. Individualization and the life course: towards a theoretical model and empirical evidence. In: Howard C (ed). Contested individualization: political sociologies of contemporary personhood. Basingstoke: Palgrave MacMillan, 2007; 61-79
11. Organisation for Economic Co-operation and Development. The looming Crisis in the Health Workforce: how can OECD countries respond? Paris: OECD, 2008.

12. Starfield B. Is primary care essential? Lancet 1994; 344: 1129-1133.

13. Kringos DS, Boerma W, Van der Zee J, et al. Europe's strong primary care systems are linked to better population health, but also to higher health spending. Health Aff 2013; 32(4): 686-694

14. Starfield B, Shi L, Macinko J. Contribution of primary care to health system and health. Milbank Q 2005; 83: 457-502.

15. Koppel A, Meiesaar K, Valtonen $\mathrm{H}$, et al. Evaluation of primary health care reform in Estonia. Soc Sci Med 2003; 56: 2461-2466.

16. Kringos DS, Boerma WGW, Spaan E, et al. A snapshot of the organization and provision of primary care in Turkey. BMC Health Serv Res 2011; 11(1): 90.

17. Boerma WGW, Groenewegen PP, Van der Zee J. General practice in urban and rural Europe: the range of curative services. Soc Sci Med 1998; 47(4): 445-453.

18. Macinko J, Starfield B, Shi L. The contribution of primary care systems to health outcomes within Organization for Economic Co-operation and Development (OECD), 1970-1998. Health Serv Res 2003; 38(3): 831-865.

19. Kringos DS, Boerma WGW, Bourgueil Y, et al. The European Primary Care Monitor: structure, process and outcome indicators. BMC Fam Pract 2010; 11(1): 81-98.

20. Kringos DS. The strength of primary care in Europe. Utrecht: NIVEL/University of Utrecht, 2013

21. Liseckiene I, Boerma W, Milasauskiene Z, et al. Primary care in a postcommunist country 10 years later: comparison of service profiles of Lithuanian primary care physicians in 1994 and GPs in 2004. Health Policy 2007; 83(1): 105-113. 